\title{
The Association of Physical Access With the Interval Between Attending the Hospital and Receiving Service in Emergency Department
}

\author{
MohammadReza Maleki ${ }^{1}$; Kamran Haji Nabi ${ }^{2}$; Ali Ayoubian ${ }^{3}$; Zahra Hashemi Dehaghi ${ }^{4, *}$ \\ ${ }_{1}^{1}$ Department of Health Care Management, Iran University of Medical Sciences, Tehran, IR Iran \\ 2 Department of Economics and Management, Islamic Azad University, Tehran Science and Research Branch, Tehran, IR Iran \\ ${ }_{3}^{3}$ Hoppital Management Research Center, Iran University of Medical Sciences, Tehran, IR Iran \\ 4 Eye Research Center, Tehran University of Medical Sciences, Tehran, IR Iran
${ }^{4}$ Eospitan \\ ${ }^{*}$ Corresponding Author: Zahra Hashemi Dehaghi, Department of Health and Treatment Services Management, Eye Research Center, Tehran University of Medical Sciences, Tehran, IR \\ Iran. Tel: +98-2188622611, E-mail: hashemi_mitra@yahoo.com
}

Received: June 13, 2014; Revised: July 16, 2014; Accepted: August 25, 2014

\begin{abstract}
Background:The relation between physical access in emergency department(ED) and the time patients have to wait before being served is unknown.

Objectives: Our objective was to discover the associations between the physical access in ED and the time patients had to wait before receiving services.

Materials and Methods: In this cross-sectional study, statistical society comprised two portions, namely, public hospitals' EDs and referred patients to the ward. Data on waiting time for 240 patients in six public and private hospitals were gathered. In addition, physical condition of EDs was inspected by visiting these hospitals. A designed checklist, based on the introduced physical space, was filled for each hospital. Results of the checklist were scored using Likert's five-points scale and Spearman and Pearson's correlation coefficient were applied to determine the relationship between physical access and waiting time.

Results: The correlation between the waiting time beginning from the very moment of stepping into the ward until first examination and physical condition at the triage wards in private $(\mathrm{P}<0.001)$ and public hospitals $(\mathrm{P}>0.05)$ was not significant. The waiting interval, beginning from the very moment of stepping into the ward until first examination and access to physical space of ED, was significant for private hospitals $(\mathrm{P}<0.001)$ and insignificant for public hospitals $(\mathrm{P}>0.05)$.

Conclusions: According to the results, there was a direct correlation between access to physical space in ED and waiting time. In addition, improving the physical access did not necessarily result in shorter waiting time. Therefore, to improve triage process, improvement of waiting time indices, and modifying forms of work process in ED are recommended.
\end{abstract}

Keywords:Emergency Medical Services; Emergency Services; Hospital; Triage

\section{Background}

Emergency department (ED) is considered as the heart of the hospital $(1,2)$. Essentiality of provision of urgent, proper, and effective complex services makes ED a unique and important section of the hospital $(1,3)$. ED needs special organization to perform its tasks. Before implementation, all procedures of ED must be examined accurately. Under an effective management, the whole system might offer reliable services to patients $(4,5)$. Many patients are referred to the ED as the first part of hospital to assess and treat patients. Referred patients to ED usually needs provision of urgent aids; hence, proper perception of the situation by the staff is of paramount importance $(4,6)$. Moreover, Ministry of Health of Iran requires realization of minimum criteria by EDs of private and public hospitals before being eligible for practical assessments. Thus, failing to achieve these minimum criteria disqualifies the standard status of the hospital (7). Many studies have pointed out decent facilities and provision of required equipment as essential factors of an ED for proper reaction to emergency situation (8). On the other hand, efficient procedure design and reducing waiting time are other important factors for an ED (9). Inefficiency of procedures at three stages of admission in the ED, provision of emergency services, and patient discharge is due to long waiting time in ED. Along with negative effects on improvement of patient's conditions, it results in development of negative attitudes toward ED and the staff. Long procedure of providing medical services to a patient in ED lessens the chance of other probable referrals for receiving the services and increases mortality rate and dissatisfaction $(1,10,11)$. Results by a study in the United States showed that overcrowded ED, caused by slow provision of services, limits the capacity of the ED and quality of the service. The study also pointed out a negative association between waiting time and patients' satisfaction with the services. That is, the higher the waiting time is, the poorer the quality of services would be perceived (12). Proper time management in ED demands

Copyright ( ) 2014, Iranian Red Crescent Medical Journal; Published by Kowsar. This is an open-access article distributed under the terms of the Creative Commons Attribution-NonCommercial 4.0 International License (http://creativecommons.org/licenses/by-nc/4.0/) which permits copy and redistribute the material just in noncommercial usages, provided the original work is properly cited. 
utilization of logical decision making (13). Apparently, suitable facility architecture of the ED is an effective factor on waiting time. Regarding the absence of a study on the association between accesses to ED and waiting time, the present study aimed to investigate the association based on the time and physical indices, dictated by Iran Ministry of Health.

\section{Objectives}

The present study aimed to discover the association between physical access in ED and the waiting time before being served in Tehran hospitals

\section{Materials and Methods}

\subsection{Settings and Participants}

In this cross-sectional study, the patients' records in EDs were investigated. A total of 240 samples were randomly selected from six hospitals: three public hospitals (Loghman-e-Hakim, Farabi, and Amir Alam) and three private hospitals (Resalat, Atieh, and Aban).

\subsection{The Instrument}

Two checklists were used for data gathering. The first one consisted of two parts: hospital and EDs information; and information of architecture and physical design of the ED, based the defined standards by the Ministry of Health (7). The second checklist measured pace of emergency services provision and was used to compare the actual records and the dictated standards by the Ministry of Health.

\subsection{Data Gathering and Analysis}

This cross-sectional study was performed in 2011 in six selected hospitals in Tehran,, Iran. The hospitals were selected after consulting with the Ministry of Health, Treatment, and Medical Education. The criteria for selecting hospitals were as following: 1 ) having secured first-grade services certificate for two consecutive years; 2) having secured first-grade services certificate for ICU and CCU; 3) running quality improvement to promote the quality of the services and supporting pertinent research work; and 4) a running ED. Characteristics of the hospitals are listed in Table 1. Patients who were referred to ED were included. Therefore, new patients replaced those removed from the study. Participants were selected orderly and randomly. Finally, 240 patients from six hospitals were recruited, while waiting time was obtained from their medical records. The sample size was calculated using the following formula:

$$
n=\frac{Z_{a}+Z_{\beta}^{2}}{c}
$$

$$
n=0.5 \times \operatorname{Ln}[(1+\mathrm{r}) /(1-\mathrm{r})]
$$

Where $r$ is correlation coefficient, $\alpha=0.05$, and power $=80 \%$.

Two aforementioned checklists were used for data collection. The checklist on hospitals and EDs had eight questions about general information of hospital and ED and number of referrals to the ED and triage ward. The checklist of architecture and physical design dealt with different aspects of location of ED in the hospital, access from outside, location of triage ward, access to triage ward, location of signs, access ways, and emergency exits. It consisted of 46 questions with five choices: quite bad, bad, not good not bad, good, and quite good that corresponded to $0,1,2,3$, and 4 , respectively. The checklists were filled by the researcher at site.

The checklist on work procedure in ED consisted of two questions. Regarding delay time, 240 files (40 files per hospital) were randomly selected. Data on waiting time until first medical check and hospitalization term (interval between admission and discharge) was gathered from the patients' records. To ascertain validity of the checklists, they were presented to ten members of faculty boards of universities and managers of the hospitals with pertinent experience. According to Cronbach's alpha, reliability of the checklists was calculated at 0.92. Descriptive statistics were used for data analyzing (SPSS 18, SPSS Inc., Chicago, IL, USA). In addition, the interval between the admission to the ED and discharge from ED was measured in minutes. For describing access way and physical design of the ward, the Pearson and Spearman's correlation coefficients were used. To observe ethical codes in performing the study, the authorities were informed beforehand and the results were presented to the hospitals while keeping confidentiality of the information.

\section{Results}

Out of six hospitals, four had employed a bachelor of nursing in charge of triage, one had an emergency technician, and one did not run triage ward. EDs were located in the ground floor in three hospitals and outside the main building in three others. All triage staff had received required trainings (Table 2). Furthermore, during the research period (spring and summer of 2010), Amir Alam Hospital with 1450 referral and Farabi Hospital with 70000 referral had the minimum and maximum number of patients, respectively (Figure 1). Based on the results, mean score of the location of triage ward for the public and private hospitals was 2.33 and 2.53, respectively. The mean score for both groups of the hospitals was 2.43 out of 4 . The association between the waiting time from admission through first medical check and location of triage in hospitals is presented in Table 3. Correlation coefficients of the mean of waiting time (from admission through first medical check) and score of triage ward lo- 
cation in all hospital and private hospitals under study were 0.3 and 0.5 respectively $(\mathrm{P}<0.001)$. The coefficient for public hospital was not significant. In addition, mean score of access to triage ward for the public hospital was 2.66 and 3.33 for the private hospitals. The mean score for both groups of the hospital was 3 out of 4 . The data regarding the association of interval between admission to first medical check with access to triage in hospitals is presented in Table 3. Correlation coefficients of mean waiting time (from admission to first medical check) and score of access to triage ward in all hospitals, private, and private hospitals were $0.006,-0.03$, and 0.12 , respectively. P value shows no significant association between the two variables. Based on the results, mean score of access to triage ward in public hospital is 2.66 and 3.33 in private hospitals. The mean score for both groups of the hospital was 3 out of 4 . The association between the waiting time from admission to first medical check and access to triage in hospitals is presented in table 4. Correlation coefficients of mean waiting time (from admission to first medical check) and score of access to triage ward in all hospitals, private, and public hospitals were respectively -0.23 ( $\mathrm{P}$ $<0.001)$, -0.28 ( $\mathrm{P}=0.002)$, and -0.30 ( $\mathrm{P}=0.001)$. $\mathrm{P}$ value shows a significant association between the two variables. Based on the results, mean scores of access to tri- age ward in the public and the private hospitals were 2.44 and 2.76 , respectively. The mean score for both groups of the hospital was 2.60 out of 4 . The association between the waiting time from admission to first medical check and access to ED in hospitals is presented in Table 5. Correlation coefficients of mean waiting time (from admission to first medical check) and score of access to ED in all hospitals and private hospitals were 0.35 and 0.50 (P $=0.001)$, respectively. In addition, the association was not significant for public hospitals.

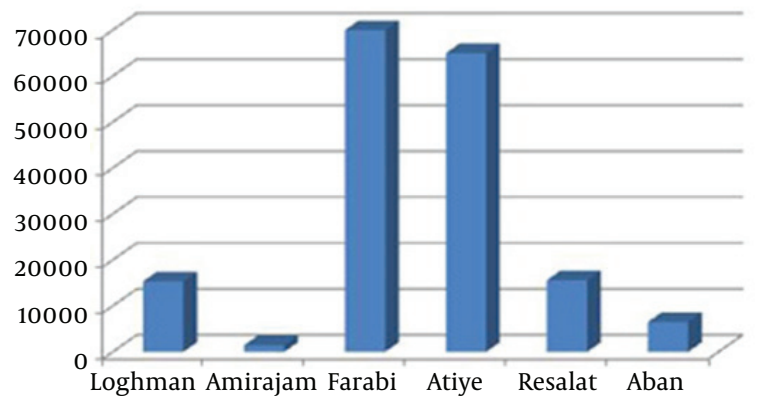

Figure 1. Number of Referral to Emergency Department in the Six-Month Period of the Study

\begin{tabular}{|c|c|c|c|c|}
\hline Type of Hospitals & Number of Hospitals' Beds & Evaluation Degree & General or Specialized & Referral \\
\hline \multicolumn{5}{|l|}{ Public } \\
\hline Amir Alam & 227 & Usual A & General, Specialized in ENT & Yes \\
\hline Farabi & 227 & Usual A & General, Specialized in eye & Yes \\
\hline Loghman & 420 & Usual A & General, Specialized in Poisoning & Yes \\
\hline Private & & & & Yes \\
\hline Resalat & 96 & Usual A & General & Yes \\
\hline Atiyeh & 96 & Usual A & General & Yes \\
\hline Aban & 96 & Usual A & General & Yes \\
\hline
\end{tabular}

Table 2. Specification of Hospitals and Emergency Departments in the Studied Hospitals

\begin{tabular}{lc}
\hline Variables & Frequency $(\%)$ \\
\hline Location of Emergency Department In Hospital & $3(50)$ \\
\hline Separate From the Hospital Main Building & $3(50)$ \\
\hline Inside the Hospital Main Building, Ground Floor & $4(66.7)$ \\
\hline Adjacent to Hospitalization Ward & $2(33.3)$ \\
\hline Yes & $4(66.7)$ \\
\hline No & $0(0)$ \\
Triage in Charge Present in Emergency Department & $1(16.7)$ \\
Bachelor of Nursing & $0(0)$ \\
Health Assistance & $1(16.7)$ \\
Emergency Technician & $6(100)$ \\
Physician & $0(0)$ \\
No Triage Service & \\
Trained Triage Nurse & \\
\hline Yes & \\
\hline No & \\
\hline
\end{tabular}


Maleki M et al.

Table 3. Waiting Time and Access to Triage Ward in the Studied Hospitals

\begin{tabular}{lcccc}
\hline Title & $\begin{array}{c}\text { Mean Interval Between Admission and Re- } \\
\text { ceiving First Medical Attention, min }\end{array}$ & $\begin{array}{c}\text { Mean Score of Physical Location } \\
\text { of Triage Unit }\end{array}$ & $\begin{array}{c}\text { Correlation Coefficient } \\
\text { Waiting Time and Physical Location of Triage Ward in the Hospitals }\end{array}$ & Palue \\
\hline Public & 5.4 & 2.33 & 0.1 & 0.27 \\
\hline Private & 4.83 & 2.53 & 0.50 & $<0.001$ \\
\hline Total & 5.11 & 2.43 & 0.3 & 0.001 \\
\hline Public & Distribution of Waiting Time and Accessibility of Triage Unit & 0.12 & 0.17 \\
\hline Private & 5.4 & 2.55 & 0.03 & 0.72 \\
\hline Total & 4.83 & 3.33 & 0.006 & 0.92 \\
\hline
\end{tabular}

Table 4. Distribution of Waiting Time and Access to Triage Ward in the Hospitals

\begin{tabular}{lcccc}
\hline Hospital & $\begin{array}{c}\text { Mean Waiting time (Admission to first } \\
\text { Medical Check) }\end{array}$ & \begin{tabular}{c} 
Mean Score of Triage Ward Location \\
\cline { 2 - 5 }
\end{tabular} & & \multicolumn{2}{c}{ Test } \\
\hline Public & 90.8 & 2.66 & -0.30 & 0.001 \\
Private & 94.6 & 3.33 & -0.28 & 0.002 \\
All & 92.7 & 3 & -0.23 & $<0.001$ \\
\hline
\end{tabular}

Table 5. Distribution of Waiting Time and Access to Emergency department in the Hospitals

\begin{tabular}{lcccc}
\hline Hospital & $\begin{array}{c}\text { Mean Waiting Time (Admission to First } \\
\text { Medical Check) }\end{array}$ & $\begin{array}{c}\text { Mean Score of Access to Triage Ward } \\
\text { Location }\end{array}$ & \multicolumn{2}{c}{ Test } \\
\cline { 2 - 5 } & Correlation Coefficient & P Value \\
\hline Public & 5.4 & 2.44 & 0.10 & 0.27 \\
Private & 4.83 & 2.76 & 0.50 & $<0.001$ \\
All & 5.11 & 2.60 & 0.35 & $<0.001$ \\
\hline
\end{tabular}

\section{Discussion}

Six hospitals ( 3 publics and 3 privates) were studied for access to ED and its association with waiting time for the patients. The mean score of ED location in the hospitals was $3.13 \pm 0.67$. The mean score of triage location in the hospitals was $2.43 \pm 0.95$. The mean score of access to ED was $3.00 \pm 0.89$. Finally, mean score of access to ED was $2.74 \pm 0.56$. Correlation coefficient for association of the mean of interval between admission and first medical check with score of triage ward location for all hospitals and the private hospitals were 0.3 and 0.5 , respectively $(\mathrm{P}<0.001)$. The association for the public hospital was not significant. Correlation coefficient between mean interval, from admission to first medical check, and score of access to triage ward for all the hospitals, public hospitals, and private hospitals were $0.006,-0.03$, and 0.12 , respectively, however, none of the association were significant. Correlation coefficient between mean interval, from admission to first medical check, and score of access to triage ward for all the hospital, the private hospitals and the public hospitals were -0.23 ( $\mathrm{P}<0.001)$, $-0.28(\mathrm{P}=0.002)$, and $-0.30(\mathrm{P}=0.001)$, respectively. The data showed significant association between waiting time in ED and score of access to triage ward. Correla- tion coefficient between mean interval, from admission to first medical check, and score of access to ED for all the hospital and the private hospitals were 0.35 and 0.50 , respectively $(\mathrm{P}<0.001)$. Regarding the public hospitals, the association was not significant. The present study revealed that mean waiting time to receive first medical care for the public and private hospitals were 5.4 and 4.84 minutes, respectively. In addition, mean of the patients' stays in ED in the public and private hospitals were 90.8 and 94.6 minutes, respectively. In this way, waiting time was longer in the private hospital than in the public hospitals. Shirani et al. conducted a comparative study on medical emergency system in Germany, France, the United States, Australia, and Iran. They assessed variables such as general organization of emergency system, human force, communications, transportation, training the staff, and public trainings. The comparison took economic as well as social conditions and available facilities into account and proposed an emergency medical system model for Iran (14). Jalili surveyed patients waiting time in ED for selected hospitals in Tehran, which were affiliated to Welfare State Organization. The survey focused on five elements in- 
cluding the waiting time from triage to first medical intervention, waiting time for diagnostic measures, time from completion of diagnosing to re-examination, time from re-examination to secondary medical intervention, and time from completion of secondary medical intervention to discharge from the ward (15). The role of pace and quality of services of children ED in a clinic affiliated with Iran University of Medical Sciences was the subject of Tabibi et al. who measured waiting time, provision of the services, and satisfaction with the services and compared the results with international standards (16). Furthermore, the results showed significant association of interval between admission and first medical check with location of triage in the private hospitals $(\mathrm{P}<0.001)$. Regarding the public hospitals, the association was not significant, which was consistent with O'Connor (17). As found by Cheraghi et al. mean of waiting time was reduced by running triage ward. Cheraghi et al. stated that mean waiting time, from triage to discharge from ED, was 73.1 minutes (18). The results demonstrated significant association between access to triage ward and waiting time in ED for all the studied hospitals. This is consistent with Lambe et al. (19). They argued that waiting time was highly changeable as 5\% of the patients spent 49 minute or longer in triage ward for receiving service. Both studies confirmed that triage ward was effective on stay time in ED. Moreover, the interval between admission to first medical check had no significant association with access to triage ward. This was in contrary to Ardagh et al. (20), who argued that fast triage service reduces waiting time for first medical check. Apparently, access to triage ward and provision of triage service at entrance to ED affects total spent time in ED, but our results showed that waiting time in triage was not effective in providing services faster. Majority of the referrals to EDs of the hospitals needed medical attention; hence, the long waiting time is not defendable and is in contrary to the executive guidelines of optimizing ED. Generally, the type of the hospital (private or public) is an effective factor in the waiting time (21). In addition, our results showed positive and significant association between access to the facilities and waiting time in the private hospitals. However, this association was not significant in the public hospitals. There is a need to review national standards regarding waiting time for receiving medical services in ED. Evidently, Ministry of Health, Treatment, and Medical Education is in charge of health system. Therefore, the Ministry needs to take measures to lead the managers of ED toward improvement of internal affairs, based on specific conditions and facilities. Clearly, this entails training the staff and informing the referred patients to ED. Moreover, the measures require support from middle and top managers of hospitals to achieve favorable results. Moreover, improvement of triage service and waiting time for the services in ED depends on reviewing work procedure in the EDs.

\section{Acknowledgements}

This a article was based on the dissertation of the corresponding author and the authors would like to thank all the professors of Economy and Management Faculty, Research Science University, who made direct or indirect contribution in conducting the study and composing the article.

\section{Authors' Contributions}

All of the authors participated in designing the research. Mohammad Reza Maleki, Kamran HajiNabi, and Ali Ayoubian were responsible for data collection. Zahra Hashemi Dehaghi was responsible for analysis and prepared the manuscript. All authors participated in reading and revising the draft and preparing the final version to submit.

\section{Funding/Support}

This study was part of MSc thesis, which was support by Islamic Azad University, Sciences and Research Branch, Tehran, Iran.

\section{References}

1. Aeenparast A, Tabibi SJ, Shahanaghi K, Aryanejhad MB. Reducing outpatient waiting time: a simulation modeling approach. Iran Red Crescent Med J. 2013;15(9):865-9.

2. Cheung WW, Heeney L, Pound JL. An advance triage system. Accid Emerg Nurs. 2002;10(1):10-6.

3. Duckett S, Nijssen-Jordan C. Using quality improvement methods at the system level to improve hospital emergency department treatment times. Qual Manag Health Care. 2012;21(1):29-33.

4. Ameryoun A, Pourtaghi G, Yahaghi E, Heidari S, Bahadori M, Ebrahimnia $\mathrm{M}$, et al. Outpatient and inpatient services satisfaction in Iranian military hospitals. Iran Red Crescent Med J. 2013;15(9):843-7.

5. Weiner SG, Totten VY, Jacquet GA, Douglass K, Birnbaumer DM, Promes SB, et al. Effective teaching and feedback skills for international emergency medicine "train the trainers" programs. Emerg Med. 2013;45(5):718-25.

6. Vescio LM, Donahoe SP, Gentile C. An organization-wide approach to improving ED patient satisfaction: one community teaching hospital's experience. J Emerg Nurs. 1999;25(3):192-6.

7. Ministry of Health. .Treatment and Medical Education. Office eva medic code stand, draft instr establishing emergen wards train medic hospitals Ir. 1998.

8. Turoff M, Chumer Md, Walle BV, Yao X. The design of a dynamic emergency response management information system (DERMIS). J Inform Technol Theory Applicat. 2004;5(4).

9. Seymour CW, Kahn JM, Martin-Gill C, Callaway CW, Angus DC, Yealy DM. Creating an infrastructure for comparative effectiveness research in emergency medical services. Acad Emerg Med. 2014;21(5):599-607.

10. Cassidy-Smith TN, Baumann BM, Boudreaux ED. The disconfirmation paradigm: throughput times and emergency department patient satisfaction. JEmerg Med. 2007;32(1):7-13.

11. Allen R, Judkins-Cohn T, deVelasco R, Forges E, Lee R, Clark L, et al. Moral distress among healthcare professionals at a health system. JONAS Healthc Law Ethics Regul. 2013;15(3):111-8.

12. Vieth TL, Rhodes KV. The effect of crowding on access and quality in an academic ED. Am JEmerg Med. 2006;24(7):787-94.

13. Aeenparast A, Farzadi F, Maftoon F. Waiting time for specialist consultation in Tehran. Arch Iran Med. 2012;15(12):756-8.

14. Shirani F, Jalili M, Asl EsH. Discharge against medical advice from emergency department: results from a tertiary care hospital in Tehran, Iran. Eur JEmerg Med. 2010;17(6):318-21. 
15. Jalili M, Shirani F, Hosseininejad M, Asl-e-Soleimani H. Emergency department nonurgent visits in Iran: prevalence and associated factors. Am J Manag Care. 2013;19(1):e1-8.

16. Tabibi SJ, Najafi B, Shoaie S. Waiting time in the emergency department in selected hospitals of Iran University of Medical Sciences in 2007. Pejouhesh. 2009;33(2):117-22.

17. O'Connor E, Gatien M, Weir C, Calder L. Evaluating the effect of emergency department crowding on triage destination. Int $J$ Emerg Med. 2014;7:16.

18. Cheraghi AO, Barzegari H, Ahmadynejad H. Emergency department patient satisfaction survey in Golestan Hospital, Ahvaz, in 2010-13. Applied mathematics in Engineering, Management and
Technology. special issue Management Technol. 2014:387-9.

19. Lambe S, Washington DL, Fink A, Laouri M, Liu H, Scura Fosse J, et al. Waiting times in California's emergency departments. Ann Emerg Med. 2003;41(1):35-44.

20. Ardagh MW, Wells JE, Cooper K, Lyons R, Patterson R, O'Donovan P. Effect of a rapid assessment clinic on the waiting time to be seen by a doctor and the time spent in the department, for patients presenting to an urban emergency department: a controlled prospective trial. NZ Med J. 2002;115(1157):U28.

21. Choi YF, Wong TW, Lau CC. Triage rapid initial assessment by doctor (TRIAD) improves waiting time and processing time of the emergency department. Emerg Med J. 2006;23(4):262-5. 